\title{
MACHINABILITY THE AISI 316 STAINLESS STEEL AFTER PROCESSING BY VARIOUS METHODS OF 3D PRINTING
}

\author{
P. Masek ${ }^{1 *}$, T. Fornusek¹, P. Zeman¹, M. Bucko ${ }^{1}$, J. Smolik ${ }^{1}$, P. Heinrich² \\ ${ }^{1}$ Czech Technical University in Prague, Research center of Manufacturing Technology, Prague, Czech Republic \\ ${ }^{2}$ KOVOSVIT MAS Machine Tools a.s., Sezimovo Ústí, Czech Republic \\ *Corresponding author; e-mail: p.masek@rcmt.cvut.cz
}

\begin{abstract}
The importance of the 3D metal printing parts still increases in many branches of production not only for prototyping. The metal prints need machining very often to obtain specific shape, accurate dimensions as well as superior surface roughness. Internal structure of 3D metal prints differs from workpiece made by conventional processes like a rolling process. That leads to different mechanical properties and machinability of the same material grade but after different way made metal 3D printed specimen. This paper is focused on the milling of the stainless steel AISI 316L. The relative machinability of the various preparations of specimens from this material were investigated. The default standard was a rolled specimen and it was compared with a Wire Arc Additive Manufacturing (WAAM) specimen and a Laser powder cladding (LPC) process specimen. The cutting forces and roughness of a machined surface were measured. The hardness and material analysis were made to inspect the material properties of the 3D printed specimens and standard. A relative machinability was evaluated and both $3 \mathrm{D}$ printed specimens were compared with the rolled standard. The effect of the hardness of tested specimens on cutting forces was investigated and the correlation between them was evaluated. Different chemical composition and material structure manifested itself as the increased variability of force values on the measured length and with small hollows in the surface profile after machining for printed specimens. The different internal structure of printed specimens led to the worse machinability compared to the rolled specimen of AISI $316 \mathrm{~L}$ in case of surface roughness.
\end{abstract}

\section{Keywords:}

Hybrid manufacturing; Machining; Machinability; Stainless steel

\section{INTRODUCTION}

There is a very limited amount of the comparative studies between 3D print steel alloys and their equivalent wrought material. Montevecchi described that 3D printed AISI H13, which he studied, had almost three times higher hardness than the wrought steel $\mathrm{H} 13$. That led to the higher measured feed and normal feed forces [Montevecchi 2016]. The measured parameters of chosen AISI $316 \mathrm{~L}$ imply that strength of laser cladded $316 \mathrm{~L}$ is up to $60 \%$ higher than wrought material and its elongation is 10 times less [Guo 2017]. That could have essential influence on the machinability. There are few studies focusing on the milling of the ASIS 316L. They deal mainly with the improving of the surface integrity. Guo described the decreasing tendency of the surface roughness with increasing cutting speed on the laser cladded AISI 316L in various directions of the deposition. He also measured increasing trend of the cutting force on the cutting velocity. Yasir measured decreasing trend of the surface roughness with cutting speed also, but for the wrought material. He also investigated an effect of the feed rate on the hardness and found increasing dependence of the hardness on the feed rate and also cutting velocity. AISI 316L was after milling harder [Yasir 2015]. Alkali found that the surface integrity can be enhanced when using the preheating [Alkali 2015]. Čović marked the AISI $316 \mathrm{~L}$ as not properly machinable without coolant, due to extensive added heat during machining [Čović 2018].

This study was focused on the machinability of the parts made by the additive manufacturing. One of them was weld arc additive manufactured (WAAM). A hybrid WAAM Method of creating metal components using the deposition of material (Fig. 1), characterized in that it comprises the following steps [Smolík 2017]:

- Deposition of a metal layer using electric arc welding in protective atmosphere while controlling the position and parameters of arcing for the desired weld deposit shape and while controlling the volume of individual spot and bead welds forming the deposit. The fronius welder was used in this study;

- Controlled cooling to 20 to $90{ }^{\circ} \mathrm{C}$;

- Mechanical or liquid-stream cleaning; 
- Machining aimed at creating a geometrically defined surface for another weld deposit;

The aforementioned steps are repeated until the component is complete.

Deposition welding is carried out using electric arc, with continuously fed electrode (Fig. 2). It is followed by intermittent cooling of one weld bead and cleaning of the weld deposit using mechanical brushes. The front surface - a surface perpendicular to the direction of deposit growth or a surface whose normal is at an angle of no more than $45^{\circ}$ to the direction of weld growth - is also machined. It is generally a shaped surface. It is carried out using standard cutting tools for machine tools - cutters, turning tools, grinding wheels, etc., using standard procedures and too movements with respect to the component - workpiece. It is followed by surface cleaning and drying before a new weld deposit is applied - contour controlled, performed by means of a standard pneumatic system and general or controlled direction of the air stream to the surface on which the new weld deposit is to be applied. Temperature monitoring on the surface for the future weld deposit is carried out using a thermal imaging camera Flir with cleaned porthole into the working area, with an evaluation, or output of data on maximum temperature in the field of vision.

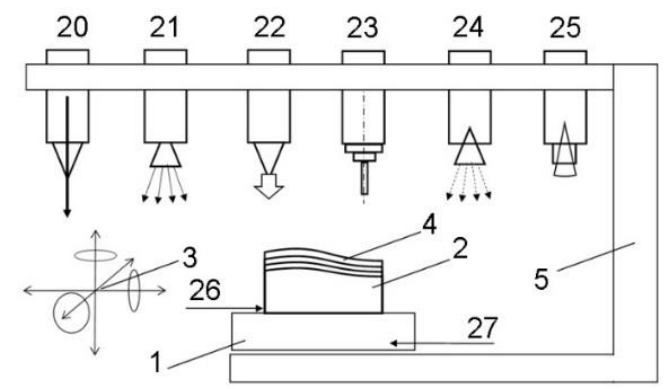

Fig. 1: WAAM method for building parts. 1 - table of machine tool; 2 - basic material; 3 - coordinate system of machine tool; 4 - welded material; 5 - frame of machine tool; 20 - welding head; 21 - intermittent cooling unit; 22 weld deposit cleaning unit; 23 - weld deposit machining unit for shape modification; 24 - surface cleaning and drying unit; 25 - temperature control unit; 26 - continuous component cooling system; 27 - continuous table/pallet cooling system.

Cold Metal Transfer technology by Fronius International

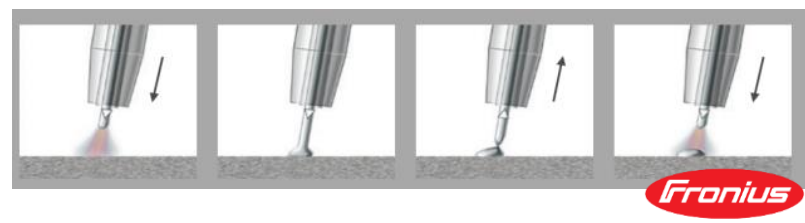

Fig. 2 : Cold Metal Transfer technology by Fronius International $\mathrm{GmbH}$ is use for additing material.

The second method of building a part by additive manufacturing was a Laser Cladding (LPC) process. That is a deposition welding of metal powder entrained in a gas stream or of a metal wire fed to the deposition welding site by a laser beam (Fig. 3). Adjustement of deposition parameters is chalenging when the aditively manufactured part had be properly build in terms of the homogenity for follow up machining as can be seen in study of Calleja [Calleja, 2014] The powder of AISI 316L was used in this study. The whole specimen was build at once without cooling or embedded aditional technological operation.
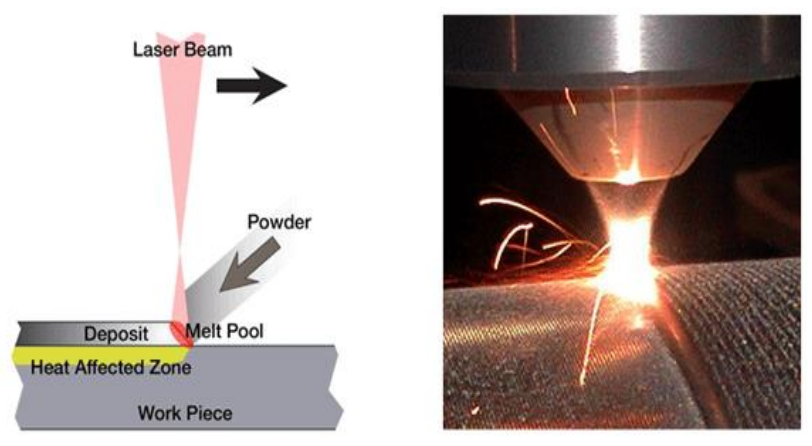

Fig. 3 : LPC method for buliding parts [Kaufold 2018].

This comparative study had main task to describe differences between specimen made by three various way from AISI $316 \mathrm{~L}$ stainless steel in term of machinability during milling.

\section{DESIGN OF EXPERIMENT}

The tested material was AISI 316 in this study. AISI 316L is a Chromium Nickel stainless steel with austenitic structure. Content of the $\mathrm{C}$ is less than $0.03 \%$. Equivalent indication to AISI $316 \mathrm{~L}$ is WNr. 1.4404 with only small differences in the chemical composition (Tab. 1). Input material for building of the specimen by WAAM or LPC method had a little bit different chemical composition. Differences are necessary due to burn of the chemical elements in the melting bath. Chemical composition could be different from wrought specimen also after the specimen building process (Tab. 2, Tab. 3). The most significant differences can be seen when elements $\mathrm{C}, \mathrm{Cr}, \mathrm{Mo}, \mathrm{Ni}$ and $\mathrm{N}$ are compared. Significant properties of the wrought AISI $316 \mathrm{~L}$ are presented in Tab. 4.

Tab. 1 : Measured chemical composition of hot rolled AISI. $316 L$.

\begin{tabular}{ccccccccc}
\hline $\mathbf{C}$ & $\mathbf{S i}$ & $\mathbf{M n}$ & $\mathbf{P}$ & $\mathbf{S}$ & $\mathbf{C r}$ & $\mathbf{N i}$ & Mo & $\mathbf{N}$ \\
\hline 0.014 & 0.54 & 1.60 & 0.04 & 0.03 & 17.1 & 1.81 & 10.2 & 0.04 \\
\hline
\end{tabular}

Tab. 2 : Measured chemical composition of AISI $316 \mathrm{~L}$ powder for $\angle P C$.

\begin{tabular}{ccccccccc}
\hline $\mathbf{C}$ & $\mathbf{S i}$ & $\mathbf{M n}$ & $\mathbf{P}$ & $\mathbf{S}$ & $\mathbf{C r}$ & $\mathbf{N i}$ & Mo & $\mathbf{N}$ \\
\hline 0.051 & 0.56 & 1.28 & 0.02 & 0.01 & 16.7 & 2.23 & 12.4 & 0.13 \\
\hline
\end{tabular}

Tab. 3 : Measured chemical composition of AISI 316L wire for WAAM.

\begin{tabular}{ccccccccc}
\hline $\mathbf{C}$ & $\mathbf{S i}$ & $\mathbf{M n}$ & $\mathbf{P}$ & $\mathbf{S}$ & $\mathbf{C r}$ & $\mathbf{N i}$ & $\mathbf{M o}$ & $\mathbf{N}$ \\
\hline 0.014 & 0.92 & 1.55 & 0.03 & 0.01 & 18.4 & 2.27 & 11.7 & 0.03 \\
\hline
\end{tabular}

Tab. 4 : General properties of the wrought AISI $316 \mathrm{~L}$.

\begin{tabular}{lcl}
\hline Quantity & Value & Unit \\
\hline Density & 8000 & $\mathrm{~kg} / \mathrm{m}^{3}$ \\
Yield modulus & 193 & $\mathrm{GPa}$ \\
Tensile strength & $500-700$ & $\mathrm{MPa}$ \\
Yield strength $\mathrm{R}_{\mathrm{p} 0,2}$ & 200 & $\mathrm{MPa}$ \\
Melting temperature & 1410 & ${ }^{\circ} \mathrm{C}$ \\
Thermal conductivity $\lambda\left(20^{\circ} \mathrm{C}\right)$ & 14 & $\mathrm{~W} / \mathrm{m}^{*} \mathrm{~K}$ \\
\hline
\end{tabular}


Three specimens of AISI $316 \mathrm{~L}$ were created. WAAM and LPC specimens were built on the base made of stainless steel with dimension $105 \times 105 \times 12 \mathrm{~mm}$. The built specimen itself was a cube with the length of a side $60 \mathrm{~mm}$. The ply of the added material was removed by milling operation into depth of $5 \mathrm{~mm}$ due to surface alignment. Wrought material was prepared from a square hot rolled rod. It was used down milling strategy with radial depth of cut $4 \mathrm{~mm}$ and axial depth of cut $2 \mathrm{~mm}$ for experimental part.

The 4 teeth coated tungsten carbide end mill with irregular pitch and changeable heads was chosen for the test. The cutting tool had signature EC160E12R05CF-4T10 908 and was made by the ISCAR company (Fig. 4,

Tab. 5).

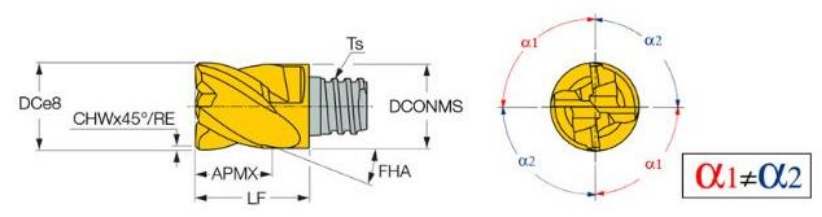

Fig. 4 : End mill head from ISCAR.

Tab. 5 : Properties of End mill from ISCAR.

\begin{tabular}{lcc}
\hline Property & Value & Unit \\
\hline Tool diameter & 16 & $\mathrm{~mm}$ \\
Edge radius & 0.5 & $\mathrm{~mm}$ \\
Number of teeth & 4 & \\
Maximal depth of cut & 12 & $\mathrm{~mm}$ \\
Helix angle & 38 & $\circ$ \\
\hline
\end{tabular}

\subsection{Material analysis}

Samples were ground on sandpaper up to P1000 grain size. Specimens where then pre-polished on canvases using BUEHLER METADI $3 \mu \mathrm{m}$ single crystal suspension. Next, samples were polished on canvas with colloidal Al2O3 BUEHLER MASTERPREP polishing suspension $0.05 \mu \mathrm{m}$. Samples were etched using STUERS Polipower as electrolyte solution of $10 \%$ oxalic acid with parameters: $5.5 \mathrm{~V}$ for $8 \mathrm{~s}$. Images were taken at: Carl Zeiss Neophot 32 + digital camera and analysis software NIS ELEMENTS AR

\subsection{Measurement of hardness}

Surface was rough machined to remove deterioration from flatness made by production process and then a thin ply was removed due to avoid of the surface layer hardening influence. The surface of the specimen was machined by the same cutting tool as for the main block of experiments but with other new head. Cutting conditions were for this preparation of the surface: cutting velocity $80 \mathrm{~m} / \mathrm{min}$, feed per tooth $0.1 \mathrm{~mm}$, axial depth of cut $0.2 \mathrm{~mm}$ and radial depth of cut $12 \mathrm{~mm}$. Hardness was measured over the whole new surface before a machining of the experimental runs. The hardness itself was measured 5 times in each of 17 places on the machined surface, see the diagram of the hardness measurement (Fig. 5).

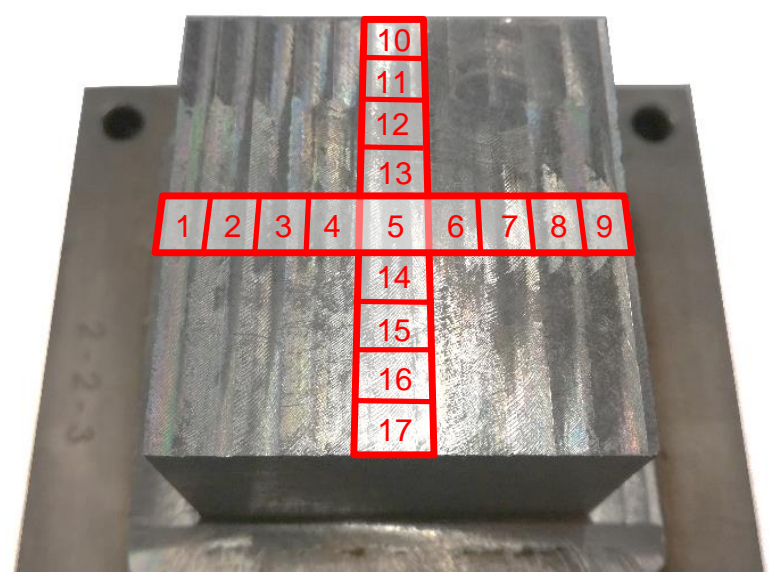

Fig. 5 :Areas of the hardness measurement on the premachined surface.

The hardness tester KT-C (Fig. 6) was used for measurement of the surfaces roughness. This tester used the Shore principles of the measurement in accordance with EN ISO 868. Values were converted to $\mathrm{HB}$ for stainless steels according to an internal configuration of the hardness tester.

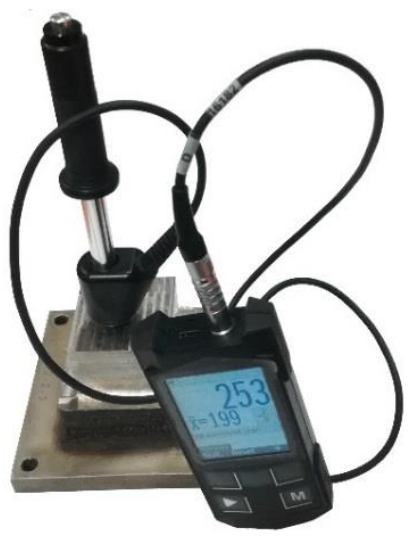

Fig. 6. Measurement of hardness with $K T-C$ tester.

\subsection{Surface roughness measurement}

Surtronic 3+ was used for the surface roughness measurement after milling (Fig. 7). Surtronic $3+$ is a portable measuring device used for a contact measurement. Surface roughness and profile were evaluated in the Tally profile Lite software. The cut-off length was chosen $0.025 \mathrm{~mm}$ according to EN ISO 4288 for all tested runs. The surface parameter $\mathrm{Ra}$ was evaluated (1) as the most commonly used surface roughness parameter.

$$
R a=\frac{1}{l} \int_{0}^{l}|Z(x) d x|
$$

The surface roughness was measured after each two experimental runs directly in the machine tool. The platform for the portable measuring device was clamped in front of the specimen on the dynamometer (Fig. 7). 


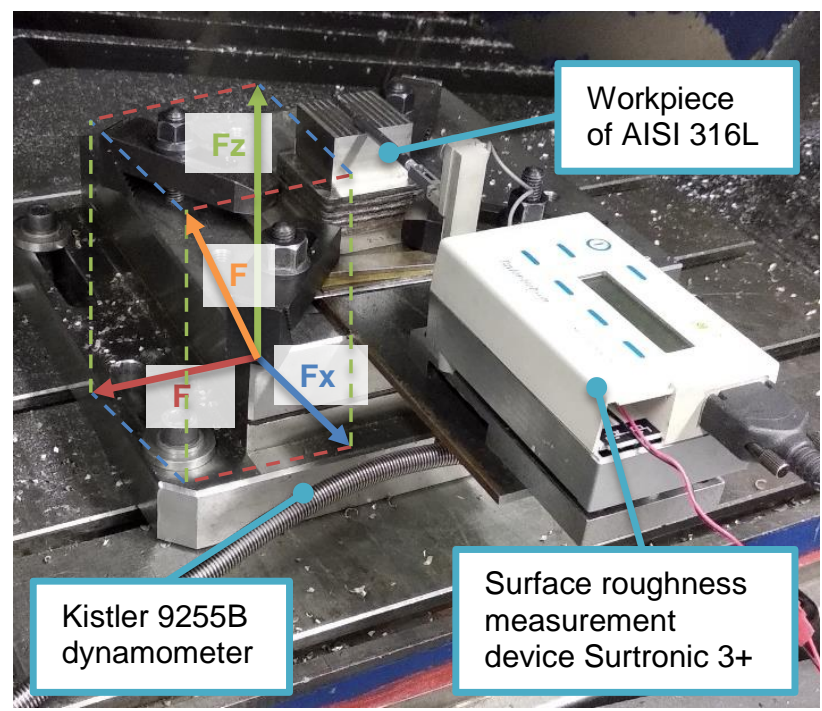

Fig. 7 : Measurement of surface roughness and cutting forces.

Three measurements of the surface roughness were taken for each run of the experimental design.

\subsection{Cutting force measurement}

Kistler 9255B dynamometer was used for measuring of the cutting force components $F_{X}$ and $F_{y}$ (Fig. 7). The dynamometer was clamped on the table of machine tool. An active force $F_{a}$ was calculated from $F_{x}$ and $F_{y}$ as a sum of squares under the square root (2). Similarly, the tota force exerted by a cutting part $F$ was calculated from the active force $F_{a}$ and passive force $F_{z}(3)$. Only $F$ was used as comparative base for tested specimens as well as between various combinations of cutting conditions in term of forces.

$F_{a}=\sqrt{F_{x}^{2}+F_{y}^{2}}$

$F=\sqrt{F_{a}^{2}+F_{z}^{2}}$

\subsection{Cutting conditions}

Three level design of experiment for two factors was proposed. The feed per tooth was proposed ranging from 0.04 to $0.1 \mathrm{~mm}$ and cutting speed from 40 to $80 \mathrm{~m} / \mathrm{min}$ (Tab. 6). Radial depth of cut was chosen $4 \mathrm{~mm}$ and axial depth of cut was $2 \mathrm{~mm}$. Experimental runs was randomized in the design to avoid the tool wear influence on the measured data.

Tab. 6 :Table of DOE.

\begin{tabular}{cccccc}
\hline Factor & Unit & Symbol & \multicolumn{4}{c}{ Levels } \\
\hline $\begin{array}{c}\text { Feed per } \\
\text { tooth }\end{array}$ & $\mathrm{mm}$ & $f_{t}$ & 0.04 & 0.07 & 0.1 \\
$\begin{array}{c}\text { Cutting } \\
\text { velocity }\end{array}$ & $\mathrm{m} / \mathrm{min}$ & $v_{c}$ & 40 & 60 & 80 \\
\hline
\end{tabular}

The 3 axis CNC vertical milling machine tool with spindle Cytec (maximum revolution $15000 \mathrm{rpm}$, power $18 \mathrm{~kW}$ and torque $70 \mathrm{Nm}$ ) was used for the milling tests.

\section{RESULTS AND DISCUSSION}

\subsection{Material analysis}

Material analysis revealed that specimens made by WAAM and LPC differ structurally. The macro image of specimen WAAM shows the individual bands of weld beads, while the structure of specimen LPC was oriented and the directions of crystal growth were evident. On the surface of the WAAM specimen was a fine intercellular structure without the presence of deformation bands with austenitic matrix and skeletal ferrite. The core of sample WAAM consists of a partially coarse to disintegrated columnar cellular structure within the bead, which becomes a coarser to finer intercellular structure. An oriented columnar cellular structure was visible on the surface of sample LPC in the absence of deformation bands. The core of LPC specimen was a mixture of columnar cellular structure and columnar oriented dendrites. Specimens WAAM and LPC further contain very fine particles, probably carbides. Rolled specimen was assumed to correspond to an austenitic structure with lamellar delta ferrite lines and deformation bands that are well visible on the surface at the machining area.

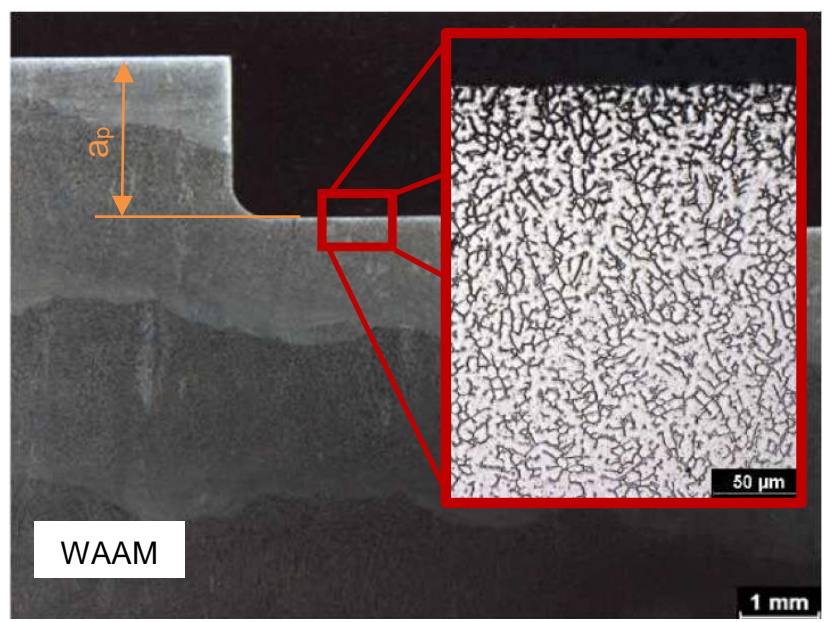

Fig. 8. Metalographic cut of WAAM specimen.

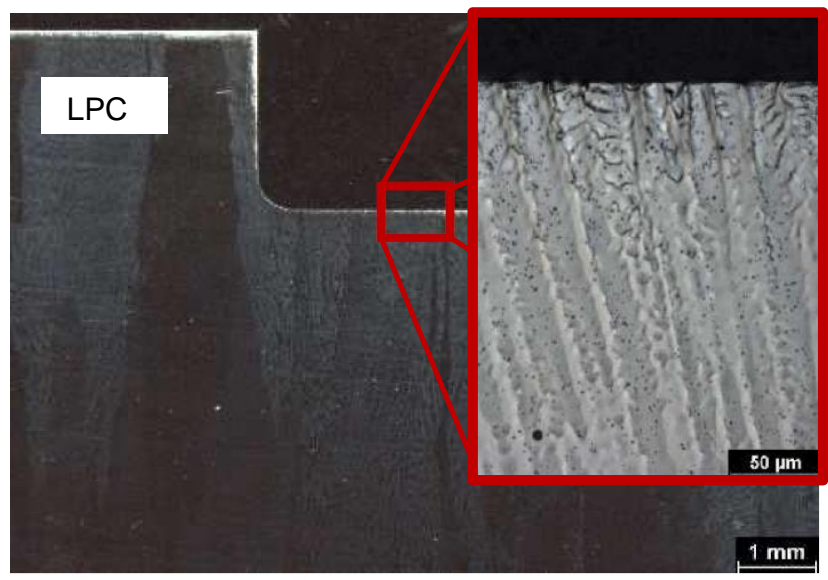

Fig. 9. Metalographic cut of LPC specimen. 


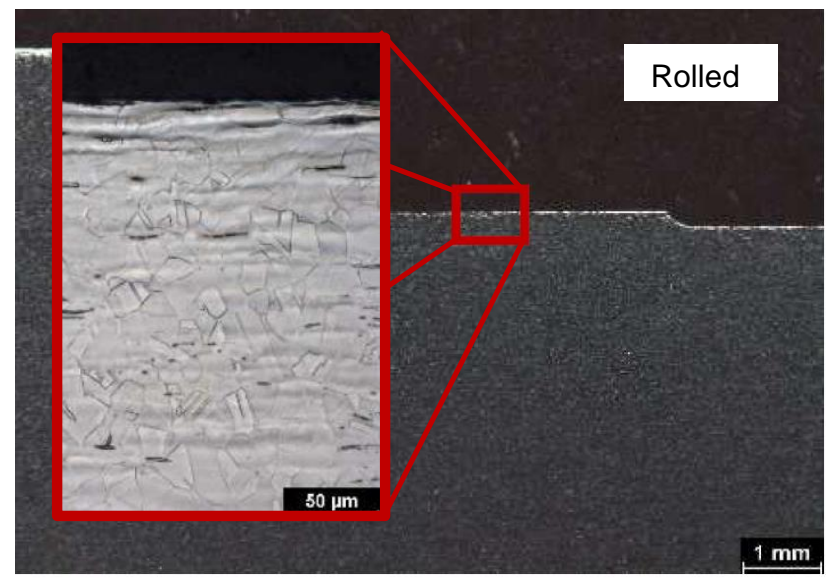

Fig. 10. Metalographic cut of Rolled specimen.

\subsection{Hardness}

The hardness was compared between all three specimens. The hardness of the rolled specimen was different from the WAAM specimen as well as from the LPC specimen, see diagrams Fig. 11, Fig. 12, Fig. 13. These diagrams show variation of the hardness from sides of specimens to the middle. The Rolled specimen had the lowest hardness in the middle and its hardness increases to the sides. That indicates variation of hardness dependence on the rolling direction. The highest average hardness had WAAM specimen with the small variance of the measured data. LPC specimen had relatively uniform hardness on the whole measured surface. The variability of the hardness for the WAAM and LPC specimen was in each of the measured point higher than variability between measuring places on the surfaces and this variability was almost 11 for LPC specimen and 13 for WAAM specimen.

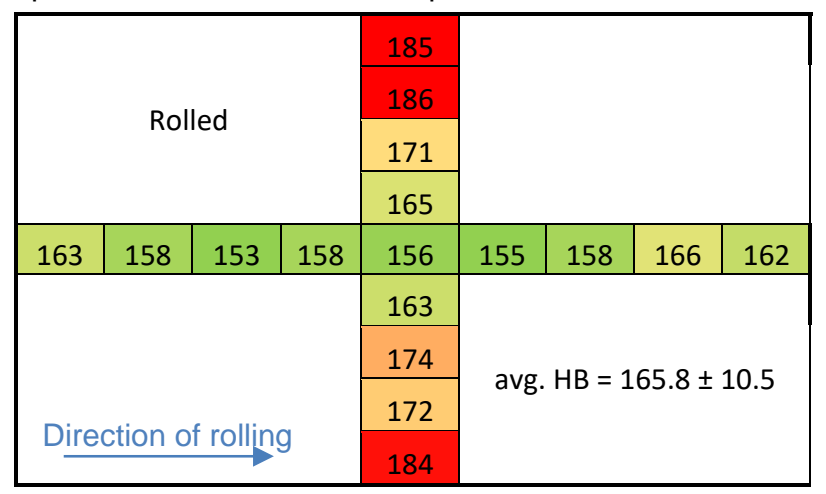

Fig. 11 : Results of hardness for the Rolled specimen.

\begin{tabular}{|c|c|c|c|c|c|c|c|c|}
\hline \multirow{2}{*}{\multicolumn{4}{|c|}{ WAAM }} & 186 & \multirow{4}{*}{192} & \multirow[b]{5}{*}{191} & \multirow[b]{5}{*}{196} & \multirow[b]{5}{*}{194} \\
\hline & & & & 182 & & & & \\
\hline & & & & 180 & & & & \\
\hline & & & & & & & & \\
\hline \multirow[t]{5}{*}{185} & 187 & 181 & 187 & 188 & & & & \\
\hline & & & & 196 & \multirow{4}{*}{ avg } & \multirow{4}{*}{. $\mathrm{HB}=$} & \multirow{4}{*}{88.8} & \\
\hline & & & & 198 & & & & 53 \\
\hline & & & & 193 & & & & \\
\hline & & & & 191 & & & & \\
\hline
\end{tabular}

Fig. 12: Results of hardness for the WAAM specimen.

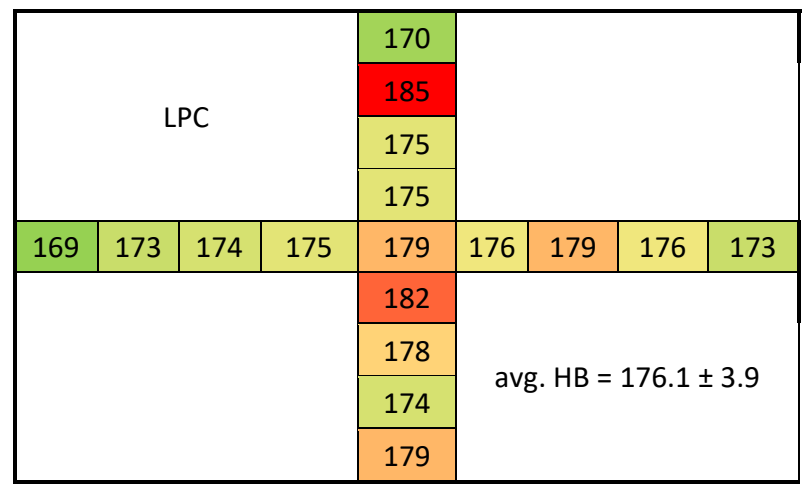

Fig. 13 : Results of hardness for the LPC specimen.

A comparison between three diffrent tested specimens did not prove correlation between hardness and cutting forces. There was no simple rule describing how the hardness of surface influences machinability of the additively prepared specimens. All tested specimens had different chemical composition due to the burn of some percent of the alloying elements during a building process and due to different chemical composition of basic material (powder or wire) This and diferent way of the specimen manufacturing led to the diferent material structure as proved the material analysis.

\subsection{Cutting forces}

Records of measured cutting force components were compared directly. This direct comparison can reveal local change of the material properties along the cut due to chemical composition and material structure. The magnitude of measured components $F_{x}$ and $F_{y}$ had the smallest variability for the rolled specimen (Fig. 14). A variability of values was much higher for additively prepared specimens. There was even a visible local dependence of the force magnitude for the WAAM prepared specimen (Fig. 15). The LPC prepared specimen show this dependence too (Fig. 16), but the variability of the total force amplitude was slightly smaller. Higher variability of the forces could be caused by higher variability of the hardness in differend areas of the measurement. That could be explained with the higher heterogeinity of the material properties of the $3 D$ printed specimens due to carbides, inclusions, impurities as well as pores included in the structure. On the other hand, the rolled specimen shows relatively uniform largeness of mesured forces dou to fine and uniform inner structure.

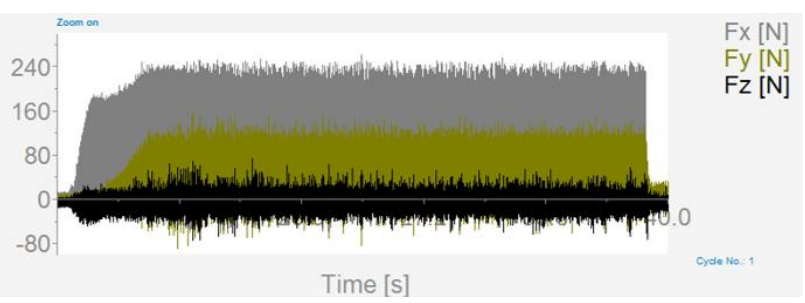

Fig. 14 : Record of forces components from milling of Rolled material $\left(f_{t}=0,04 \mathrm{~mm}, v_{c}=80 \mathrm{~m} / \mathrm{min}\right)$. 


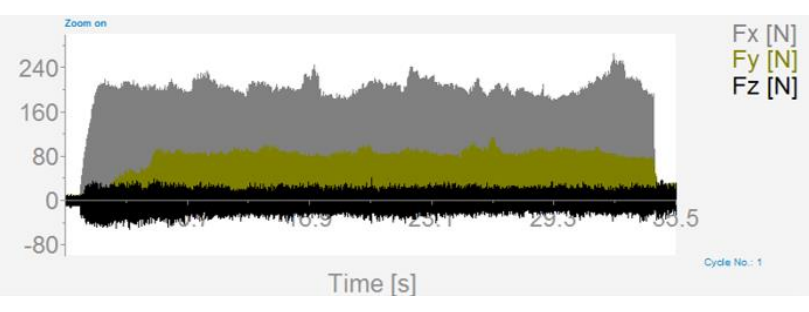

Fig. 15 :Record of forces components from milling of WAAM material $\left(f_{t}=0,04 \mathrm{~mm}, v_{c}=80 \mathrm{~m} / \mathrm{min}\right)$.

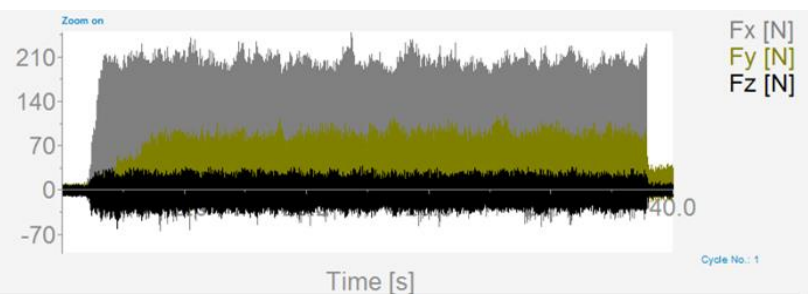

Fig. 16 : Record of forces components from milling of $L P C$ material $\left(f_{t}=0,04 \mathrm{~mm}, v_{c}=80 \mathrm{~m} / \mathrm{min}\right)$.

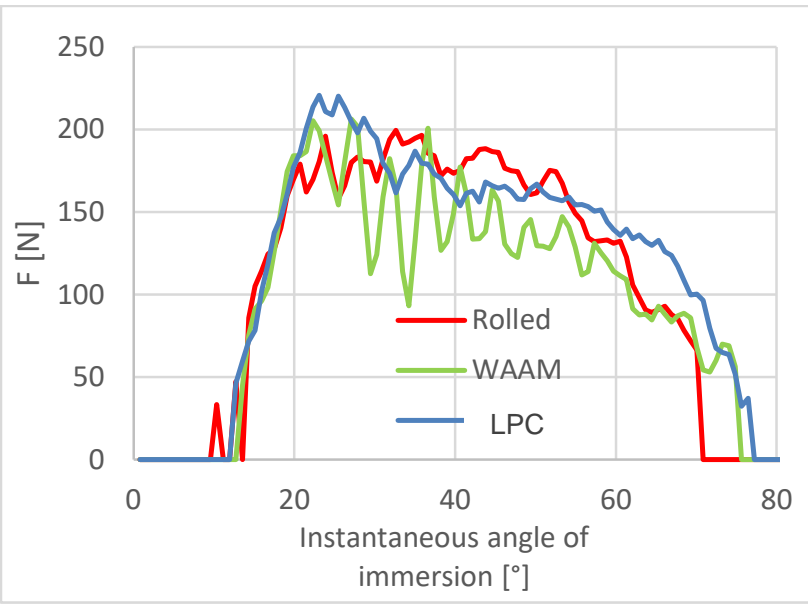

Fig. 17 : Amplitude of the total force during one engagement of the cuttig tool ( $f_{t}=0,04 \mathrm{~mm}, v_{c}=80 \mathrm{~m} / \mathrm{min}$ ).

Some differences were observed when the total force measured during the single tooth engagement. The total force oscillated a lot for the WAAM specimen in comparison with rolled or LPC specimen (Fig. 17). This could be an influence of the heterogeneity of the mechanical properties of WAAM specimen where the structure was changed in the weld pool. On the other hand, the oriented columnar cellular structure of the LPC specimen did not cause high amplitude of measured force.

The average $F$ was measured the highest for rolled specimen (Fig. 18). The material analysis of rolled specimen showed hardening of surface after machining. This is probalbly reason that this kind of specimen had higher measured forces. Hardened surface was not found on the aditively prepared specimens. When the rolled specimen was machined, the total force was decreased with increasing cutting velocity. The dependence of the tota force on the cutting velocity was opposite. This phenomenon could be initialized due to increasing strain rate in the primary and secondary deformation zone which makes hardening when the cutting velocity increases. The same phenomenon was observed by Guo [Guo, 2017]. The total force was increased steeply with feed per tooth (Fig. 18). That was caused by enlargement of the primary deformation zone with increasing chip thickness.
The WAAM specimen had a little bit smaller average $F$ than the rolled one. The smalest average total force was measured for LPC specimen. The increasing dependece of the $F$ on the feed per tooth was evaluated for all tested specimens unlike the dependece $F$ on the cutting velocity. It was higher increasing for both 3D printed specimens. The hardening process probably does not affect machining of both 3D printed specimens.

An ANOVA test was used for investigation of the cutting conditions influence on the magnitude of the total force. The $F$ was mainly affected by changing of the feed per tooth and less by changing of the cutting velocity. Nevertheless, the statistically insignificant influence of the cutting velocity was evaluated only for the case of the WAAM prepared specimen, see, Tab. 7, Tab. 8, Tab. 9. WAAM specimen showed higher forces probably due to higher measured hardness on the surface than the LPC sample.

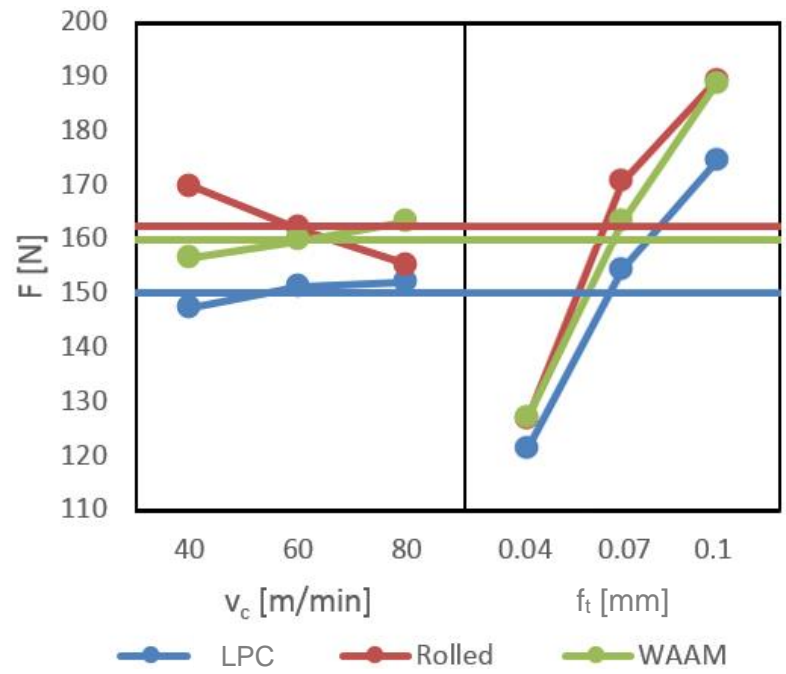

Fig. 18 : The main effect plot for means of $F$ on Rolled, $W A A M$ and $L P C$ specimen.

Tab. 7 : ANOVA results for $F$ on Rolled specimen.

\begin{tabular}{lcccccc}
\hline Source & DF & Seq SS & Adj SS & Adj MS & $\mathrm{F}$ & $\mathrm{P}$ \\
\hline $\mathrm{V}_{\mathrm{c}}$ & 2 & 652.3 & 652.3 & 326.2 & 15.9 & 0 \\
$\mathrm{f}_{\mathrm{t}}$ & 2 & 12408.5 & 12408.5 & 6204.3 & 302.47 & 0 \\
Error & 13 & 266.7 & 266.7 & 20.5 & & \\
Total & 17 & 13327.5 & & & & \\
\hline
\end{tabular}

Tab. 8 : ANOVA results for $F$ on WAAM specimen.

\begin{tabular}{lcccccc}
\hline Source & DF & Seq SS & Adj SS & Adj MS & $F$ & $P$ \\
\hline $\mathrm{V}_{\mathrm{c}}$ & 2 & 135.4 & 135.4 & 67.7 & 0.37 & 0.695 \\
$\mathrm{ft}_{\mathrm{t}}$ & 2 & 11562.1 & 11562.1 & 5781 & 31.9 & 0 \\
Error & 13 & 2355.6 & 2355.6 & 181.2 & & \\
Total & 17 & 14053.1 & & & & \\
\hline
\end{tabular}

Tab. 9 : ANOVA results for F on LPC specimen.

\begin{tabular}{lcccccc}
\hline Source & DF & Seq SS & Adj SS & Adj MS & $F$ & $P$ \\
\hline $\mathrm{V}_{\mathrm{c}}$ & 2 & 278.2 & 65.3 & 32.7 & 4.93 & 0.027 \\
$\mathrm{f}_{\mathrm{t}}$ & 2 & 7803.4 & 7803.4 & 3901.7 & 588.8 & 0 \\
Error & 12 & 79.5 & 79.5 & 6.6 & & \\
Total & 16 & 8161.2 & & & & \\
\hline
\end{tabular}

When the rolled specimen was chosen as a standard, it was possible to compare machinability of WAAM and LPC prepared specimen relatively. The relative value was calculated as a ratio of the value measured for additively 
prepared specimen to the value measured for wrought material. The relative machinability calculated across all experiments was better for the additively prepared specimen in the case of the total force. Relative number of the WAAM prepared specimen was 0.99 and relative number of the LPC prepared specimen was 0.93 . The differences between them were very small. The relative number get worse with higher cutting velocity. When the high cutting velocity was used the relative number increases and machinability of additively prepared specimens was at hight speeds worse then of standard specimen, it means relative number was higher then $1 /$ Fig. 23)

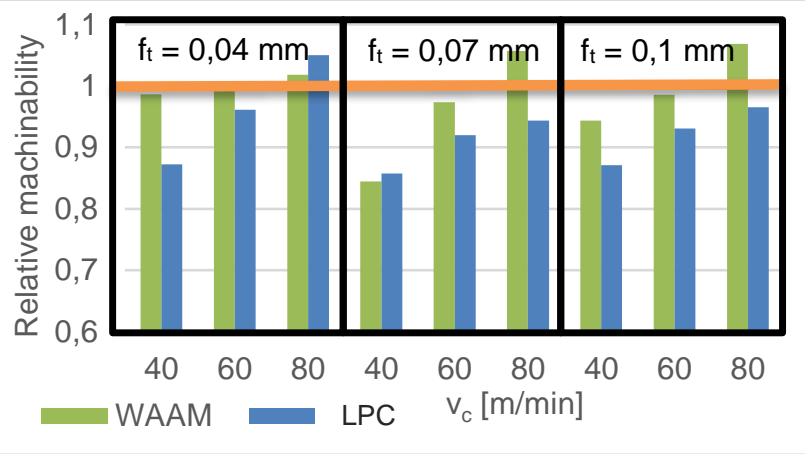

Fig. 19. Comparison of relative number - based on Ra.

It can be noticed that the additively prepared specimens show the measurable hollows which could negatively influence evaluated parameters $R a$ (Fig. 21, Fig. 22). It can be other indirect proof of the heterogeneity of the mechanical properties of the additively prepared specimens where probably softer areas were nearby harder areas and this deteriorated surface after machining. These hollows were not observed on the surface of the rolled specimen (Fig. 20).

Surface roughness was evaluated by ANOVA test and it was proved that the feed per tooth had significant influence on the surface roughness. That was proved that the cutting velocity had no statistically significant influence to parameter $R a$ in case of rolled and WAAM prepared specimen (Tab. 10, Tab. 11). It was not possible to decline zero hypothesis about equality of variances in case of the results on the LPC specimen (Tab. 12) prepared specimen on the significance level 0.05 when the $p$-value was compared with. The increasing trend was observed when the dependence $R a$ on the feed per tooth was measured (Fig. 23). The only significance dependence $R a$ on the cutting velocity was measured for LPC prepared specimen. The lowest surface roughness was evaluated for the cutting velocity $60 \mathrm{~m} / \mathrm{min}$.

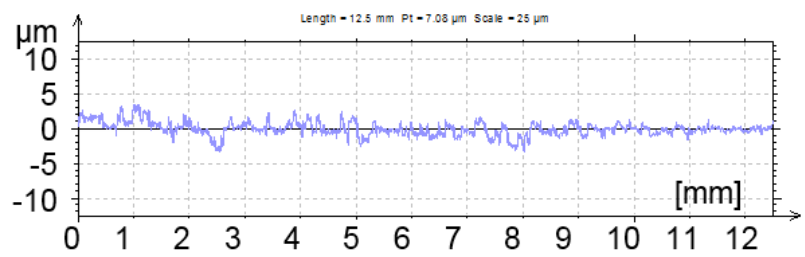

Fig. 20 : Surface profile of the rolled specimen $\left(f_{t}=0,04 \mathrm{~mm}, v_{c}=80 \mathrm{~m} / \mathrm{min}\right)$.

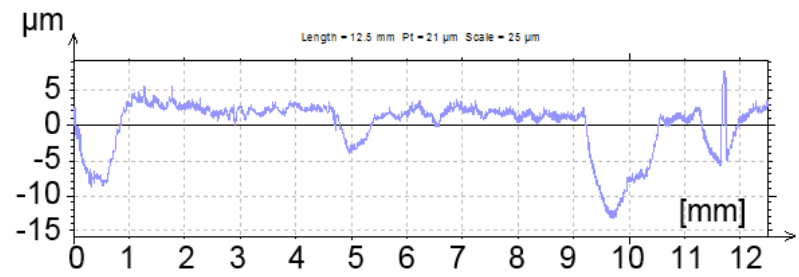

Fig. 21 : Surface profile of LPC specimen $\left(f_{t}=0,04 \mathrm{~mm}\right.$, $v_{c}=80 \mathrm{~m} / \mathrm{min}$ ).

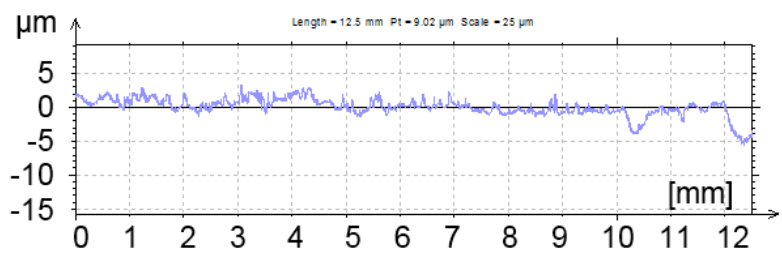

Fig. 22. Surface profile of the WAAM specimen $\left(f_{t}=0,04 \mathrm{~mm}, v_{c}=80 \mathrm{~m} / \mathrm{min}\right)$.

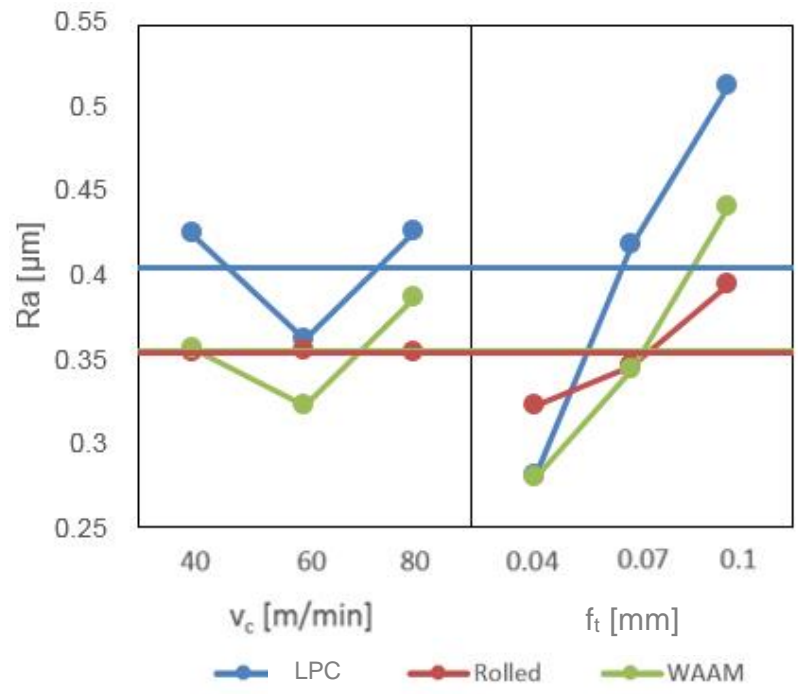

Fig. 23 : Main effect plot for means of Ra on Rolled, WAAM and LPC specimen.

Tab. 10 : ANOVA results for Ra on Rolled specimen.

\begin{tabular}{lcccccc}
\hline Source & DF & Seq SS & Adj SS & Adj MS & $F$ & $P$ \\
\hline $\mathrm{v}_{\mathrm{c}}$ & 2 & 0.0001 & 0.0001 & 0.0001 & 0 & 0.99 \\
$\mathrm{f}_{\mathrm{t}}$ & 2 & 0.04866 & 0.0487 & 0.0243 & 4.04 & 0.02 \\
Error & 49 & 0.29540 & 0.2954 & 0.0060 & & \\
Total & 53 & 0.34408 & & & & \\
\hline
\end{tabular}

Tab. 11 : ANOVA results for Ra on WAAM specimen.

\begin{tabular}{lcccccc}
\hline Source & DF & Seq SS & Adj SS & Adj MS & $F$ & $P$ \\
\hline $\mathrm{v}_{\mathrm{c}}$ & 2 & 0.03721 & 0.03721 & 0.0186 & 2.57 & 0.09 \\
$\mathrm{f}_{\mathrm{t}}$ & 2 & 0.24091 & 0.24091 & 0.1205 & 16.66 & 0 \\
Error & 49 & 0.35432 & 0.35433 & 0.0072 & & \\
Total & 53 & 0.63245 & & & & \\
\hline
\end{tabular}


Tab. 12 : ANOVA results for Ra on LPC specimen.

\begin{tabular}{lcccccc}
\hline Source & DF & Seq SS & Adj SS & Adj MS & $\mathrm{F}$ & $\mathrm{P}$ \\
\hline $\mathrm{v}_{\mathrm{c}}$ & 2 & 0.05848 & 0.0453 & 0.02265 & 3.38 & 0.04 \\
$\mathrm{f}_{\mathrm{t}}$ & 2 & 0.46822 & 0.46822 & 0.23411 & 34.93 & 0 \\
Error & 45 & 0.30161 & 0.30161 & 0.0067 & & \\
Total & 49 & 0.82831 & & & & \\
\hline
\end{tabular}

The relative number was calculated also for the surface roughness $R$. The relative machinability was better only when the feed per tooth was $0.04 \mathrm{~mm}$. The relative machinability of aditively prepared specimens was worse for any other feeds (Fig. 24).

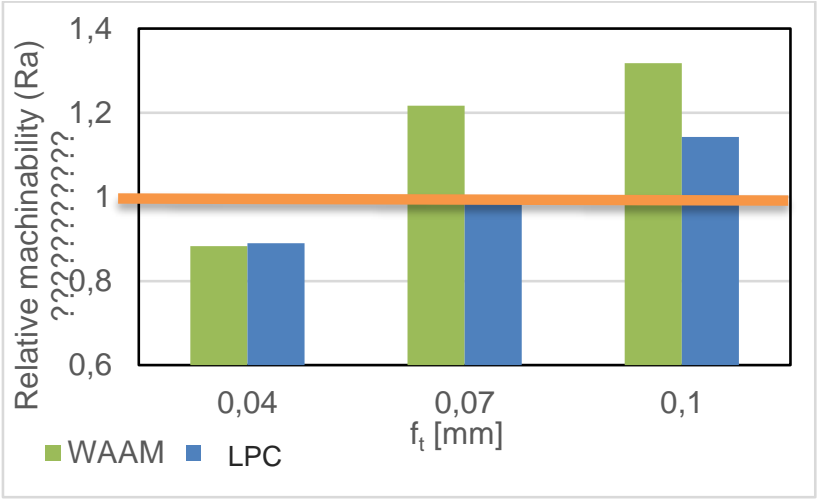

Fig. 24. Comparison of relative number - based on Ra.

That leads to recommendation to machine additively prepared AISI 316L under low cutting condition. The machinability of rolled standard of AISI $316 \mathrm{~L}$ was in other cases better then for aditively prepared specimens.

\section{CONCLUSIONS}

Three specimens made by different way were tested in terms of machinability. Two of them were made by additive manufacturing (Laser cladding of powder and welded arc additive manufacturing). The third one was chosen as a standard and was made by a hot rolling process. The study revealed several interesting facts.

- A structure and chemical composition of tested specimen differed for all tested specimens. The rolled specimen had uniform austenitic structure with visible deformation layers after machining. The WAAM and The LPC specimen did not have deformation layers. Their inner structure was not the same as for rolled specimen, but both contended carbides. The inner structure of the WAAM specimen was intercellular and the LPC specimen had columnar oriented dendrites in the structure

- $\quad$ All specimens had different hardness. The highest hardness had WAAM specimen and the lowest hardness was measured on the rolled specimen.

- Machinability of additively manufactured part of AISI $316 \mathrm{~L}$ is not possible to derive only from measured hardness because there was an influence of a manufacturing process and real a chemical composition of the material on hardening processes in specimen.
- Forces measured during machining and profiles of the surface of the additively manufactured specimen documented the heterogeneity of the mechanical properties indirectly. This results in an increased variability in the size of the measured force components. Heterogeneity of mechanical properties can be the one of the reasons of the rapid tool wear or fatal failure of cutting edge. The carefully chosen cutting conditions could decrease a risk of this failure. The dependency of the total force on the cutting velocity had an increasing trend for the additively manufactured specimens unlike the rolled one.

- Additively manufactured specimens had better machinability when low cutting conditions were chosen. Increasing cutting conditions make worse their relative machinability in the case of the total force and the surface roughness.

\section{ACKNOWLEDGMENTS}

The authors would like to acknowledge funding support from the Czech Ministry of Education, Youth and Sports under the project CZ.02.1.01/0.0/0.0/16_026/0008404 "Machine Tools and Precision Engineering" financed by the OP RDE (ERDF). The project is also co-financed by the European Union.

\section{REFERENCES}

[Alkali, 2015] Alkali, A. D. et al., 2015. Improved Surface Integrity during End Milling AISI 316L Stainless Steel Using Heat Assisted Machining, Vol. 752-753, pp. 62-67.

[Čović, 2018] Čović, M. and I. Vujović, 2018. Tool life evaluation in high speed milling of steels for shipbuilding industry. In: ICTS 2018 Portorož.

[Guo, 2017] Guo, P. et al, 2017. Study on microstructure, mechanical properties and machinability of efficiently additive manufactured AISI $316 \mathrm{~L}$ stainless steel by highpower direct laser deposition, Vol. CCXL, pp. 12-22.

[Montevecchi, 2016] Montevecchi, F. et al. 2016. Cutting forces analysis in additive manufactured AISI H13 alloy. In: Procedia CIRP, sv. 46, s. 476-79.

[Sutar, 2017] Sutar, P. A. and A.J. Gujar, 2017. Study the effect of machining parameters on surface roughness in CNC Milling of AISI 316L, Vol. X. ISSN 0974-3154.

[Yasir, 2015] Yasir, M. et al., 2015. Experimental investigation to improve surface integrity of biomedical devices by end-milling AISI 316L. September 2015.

[Smolik, 2017] CTU in Prague, Faculty of Mechaical Engineering, Department of Production Machinse and Equipment and Kovosvit MAS a.s. A method of forming metal parts by means of deposition of the material and a device for implementing this method. Inventors :Smolík, J., Diviš, I., Fornůsek, T., Malý, J. a Hosnedl, S. CZ. CZ306654B6. 19.4.2017.

[Kaufold, 2018] Kaufold R, 2018. Laser cladding technology helps manufactureres 'go green'. online: https://www.industrial-lasers.com/surface treatment. 
15th International Conference on High Speed Machining | www.hsm2019.cz

[Calleja, 2014] Calleja, A. et al. 2014. Feed rate calculation algorithm fro the homogeneous material deposition of blisk blades by 5 -axis laser cladding. International Jjournal of
Advance Manufacturing Technology. Vol.74. pp. 12191228. 